\title{
TIGAR induces p53-mediated cell-cycle arrest by regulation of RB-E2FI complex
}

\begin{abstract}
E Madan ${ }^{1,2}$, R Gogna ${ }^{2}$, P Kuppusamy ${ }^{3}$, M Bhatt ${ }^{4}$, U Pati ${ }^{*, 2}$ and AA Mahdi*,1
'Department of Biochemistry, Chhatrapati Shahuji Maharaj Medical University, Lucknow 226003, India; ${ }^{2}$ Transcription and Human Biology Laboratory, School of Biotechnology, Jawaharlal Nehru University, New Delhi 1 10067, India; ${ }^{3}$ Department of Internal Medicine, Ohio State University Medical Centre, Columbus 43210, OH, USA; ${ }^{4}$ Department of Radiotherapy and chemotherapy, Chhatrapati Shahuji Maharaj Medical University, Lucknow 226003, India
\end{abstract}

BACKGROUND: 553 induces cell-cycle arrest and apoptosis in cancer cells and negatively regulates glycolysis via TIGAR. Glycolysis is crucial for cancer progression although TIGAR provides protection from reactive oxygen species and apoptosis. The relation between TIGAR-mediated inhibition of glycolysis and p53 tumour-suppressor activity is unknown.

METHODS: RT-PCR, western blot, luciferase and chromatin immunoprecipitation assays were used to study TIGAR gene regulation. Co-IPP was used to determine the role of TIGAR protein in regulating the protein-protein interaction between retinoblastoma (RB) and E2FI. MCF-7 tumour xenografts were utilised to study the role of TIGAR in tumour regression.

RESULTS: Our study shows that TIGAR promotes p2I-independent, p53-mediated GI-phase arrest in cancer cells. p53 activates the TIGAR promoter only in cells exposed to repairable doses of stress. TIGAR regulates the expression of genes involved in cell-cycle progression; suppresses synthesis of CDK-2, CDK-4, CDK-6, Cyclin D, Cyclin E and promotes de-phosphorylation of RB protein. RB de-phosphorylation stabilises the complex between RB and E2FI thus inhibiting the entry of cell cycle from GI phase to S phase. CONCLUSION: TIGAR mediates de-phosphorylation of RB and stabilisation of RB-E2FI complex thus delaying the entry of cells in $S$ phase of the cell cycle. Thus, TIGAR inhibits proliferation of cancer cells and increases drug-mediated tumour regression by promoting p53-mediated cell-cycle arrest.

British Journal of Cancer (2012) 107, 516-526. doi:I0.1038/bjc.2012.260 www.bjcancer.com

Published online 10 July 2012

(C) 2012 Cancer Research UK

Keywords: p53; TIGAR; RB; CDK; cyclins; cell-cycle arrest; hypoxia; tumour regression

p53 induces apoptosis, cell-cycle arrest, senescence and differentiation, which prevents proliferation of stressed or damaged cells (Vogelstein et al, 2000). The role of p53 in regulation of cellular metabolism has recently been identified (Bensaad et al, 2006; Matoba et al, 2006). p53 target gene, TIGAR (TP53-induced glycolysis and apoptosis regulator), regulates glucose metabolism in cancer cells and it causes a decline in Fru-2,6- $\mathrm{P}_{2}$ levels and thereby blocks glycolysis (Bensaad et al, 2006). In addition to the regulation of glycolysis, TIGAR was shown to reduce cellular reactive oxygen species (ROS) and protect cells from DNA damage-induced apoptosis (Bensaad et al, 2006). The TIGAR protein has structural similarity with the bis-phosphatase domain of PFK-2/FBPase-2 (6-phosphofructo-2-kinase/fructose2,6-bisphosphatase). PFK-2/FBPase-2 is an enzyme that has a critical function in the regulation of cellular glycolysis. Recently, TIGAR has been shown to hydrolyse fructose-2,6-bisphosphate and fructose-1,6-bisphosphate ( $\mathrm{Li}$ and Jogl, 2009), two activities that lead to the same effects on glycolysis. Expression of TIGAR results in decreased levels of Fru-2,6- $\mathrm{P}_{2}$ and eventually negative regulation of glycolysis, which in some cells was shown to be proapoptotic. However, reduced glycolysis results in the redirection of glycolytic metabolic intermediates to the oxidative branch of the

*Correspondence: Professor AA Mahdi; E-mail: mahdiaa@rediffmail.com or Professor U Pati; E-mail: uttam@mail.jnu.ac.in

Received 23 February 2012; revised 8 May 2012; accepted I 5 May 2012; published online 10 July 2012 pentose phosphate pathway. This results in TIGAR-mediated increase in cellular NADPH production, which contributes to the scavenging of ROS by reduced glutathione and thus a lower sensitivity of cells to oxidative stress-associated apoptosis, including that induced by p53 (Bensaad et al, 2006). This brings about the question of the role of p53-mediated regulation of TIGAR in context of the tumour-suppressor role of p53, as p53-mediated transcription is designed to decrease tumorigenesis and neoplasticity. As TIGAR is proposed to be an anti-apoptotic/protective molecule, it is logical to assume that TIGAR might be related with the cell-cycle arrest and DNA repair effector response in cancer cells that suffer from repairable dose of genotoxic/cellular insult.

More than $90 \%$ of human neoplasias have abnormalities in some component of the cell cycle. Thus, the p53-mediated regulation of cell-cycle progression is a critical effector response in regulation of neoplastic growth. These abnormalities are due to regulation of the retinoblastoma $(\mathrm{RB})$ pathway or hyper-activation of $\mathrm{CDK}$ via overexpression of positive cofactors such as cyclins/CDKs or downregulation of negative factors (Hartwell and Kastan, 1994). These changes promote deregulated S-phase progression in a way that ignores growth factor signals, with loss of $G_{1}$ checkpoints (Sherr, 1996). Cell cycle is regulated by cyclin-dependent kinases (CDKs) that form heterodimer complexes with cyclins, cofactors required for the CDK activity. There are at least nine different CDKs (CDK1-CDK9) and many more cyclins (cyclin A through T) (MacLachlan et al, 1995). The cyclin/cdk complexes orchestrate the advance of the cell through different phases of its growth cycle. 
Mammalian G1 phase Cyclins D and E mediate progression through G1/S phases (Malumbres and Barbacid, 2009). Three D-type cyclins exist (Cyclin D1, D2 and D3), which are expressed differently in various cell lineages, with most cells expressing Cyclin D3 and either D1 or D2. Two types of Cyclin E (E1 and E2) exist, which show overlapping expression patterns in mouse tissues and can be co-overexpressed in human tumours (Geng et al, 2001). Mitotic cyclins $A$ and $B$ mediate progression through the $S / G 2 / M$ phases. Cyclin A1 is expressed in meiosis and early embryogenesis, whereas Cyclin A2 is found in proliferating somatic cells. Cyclin B2 probably has a role in Golgi remodelling during mitosis (Jackman et al, 1995), whereas Cyclin B1 controls other functions of this cyclin type. Until now, at least 16 cyclins have been discovered, for many of whose binding partners and functions have yet to be identified.

It has been shown that $\mathrm{RB}$ protein $(\mathrm{pRb})$ is responsible for a major G1 checkpoint (restriction point) blocking S-phase entry and cell growth, promoting terminal differentiation by inducing both cell-cycle exit and tissue-specific gene expression (Weinberg, 1995). The interaction between the pRb family proteins and the E2F family transcription factors has a central role in governing cell-cycle progression and DNA replication by controlling the expression of E2F-dependent genes (Macaluso et al, 2005). RB protein phosphorylation is a cell-cycle-dependent phenomenon and cyclin/CDK complexes are responsible for this regulation. In the early G1 phase, D-type cyclins couple with the kinase cdk 4 or cdk6 and phosphorylate pRb/105 and Rb2/p130 (Dowdy et al, 1993). In the middle to late G1 phase, Cyclins $\mathrm{E}$ and $\mathrm{A}$ form complexes with cdk2, which specifically target $\mathrm{Rb} / \mathrm{p} 105, \mathrm{Rb} 2 / \mathrm{p} 130$ and p107 (De Luca et al, 1997). This step is crucial for the inactivation of members of the $\mathrm{pRb}$ family and the release of E2F factors. pRb, which is hypo-phosphorylated in resting G0 cells, is increasingly phosphorylated during progression through G1 and is maintained in a hyper-phosphorylated state until late mitosis (Weinberg, 1995; Claudio et al, 2000). When in its actively growthsuppressing hypo-phosphorylated state, $\mathrm{pRb}$ physically associates with E2F factors and blocks their ability to activate expression of genes that encode products necessary for S-phase progression. The RB proteins repress gene transcription, required for transition from G1- to S-phase, by directly binding to the transactivation domain of E2F and by binding to the promoter of these genes as a complex with E2F (Adams and Kaelin, 1995). Progression of the cells through $\mathrm{G} 1$ and $\mathrm{S}$ phases requires inactivation of RB protein phosphorylation. The phosphorylation status of these proteins is regulated by Cdk inhibitor (CKI) binding to the cyclin/cdk complexes (Sherr and Roberts, 1995). E2F1 is required by the cell-cycle machinery for entry of cells from G1 phase to $S$ phase of cell cycle. Thus, the activity of E2F1 is tightly regulated by the RB protein (Hsieh et al, 1997; Lauricella et al, 2001). Hyperphosphorylation of RB by the CDK4/6-Cyclin D complex leads to the dissociation of $\mathrm{pRb}$ from its binding partner E2F1, which helps in S-phase entry (Wang et al, 1999).

Here we show that p53-inducible TIGAR has an important role in regulation of cell-cycle progression. TIGAR promotes G1-phase arrest in cancer cells by negatively regulating the expression of the members of cyclin-CDK complex which are responsible for phosphorylation of the RB protein. The TIGAR-mediated RB hypo-phosphorylation results in stabilisation of RB-E2F1 complex and thus restricts the entry of cells into S-phase. The present study establishes that TIGAR-mediated G1 arrest is an alternative pathway to p21-induced arrest.

\section{MATERIAL AND METHODS}

\section{Cell lines and culture conditions}

MCF-7 and KB cells were obtained from the National Center for Cell Sciences (Pune, India). The cells were cultured as monolayers in DMEM medium supplemented with $10 \%(\mathrm{v} / \mathrm{v})$ heat-inactivated fetal bovine serum and antibiotics, and incubated at $37^{\circ} \mathrm{C}$ in a humidified atmosphere of $95 \%$ air and $5 \% \mathrm{CO}_{2}$.

\section{Transfections}

p53 siRNA and TIGAR siRNA were obtained from Santa Cruz Biotechnology (Santa Cruz, CA, USA). Cells were split 2 days before transfection at the density of $5 \times 10^{5}$ cells per plate. siRNA were transfected in cells using ESCORT IV kit (Sigma, St Louis, $\mathrm{MO}$, USA). In vivo cDNA transfections were made using in vivo transfection kit from Altogen Biosciences (Las Vegas, NV, USA).

\section{Tumour induction}

A 80 - $\mu$ l cell suspension containing $1 \times 10^{7}$ cells was subcutaneously injected into the hind legs of each mice, thus producing a site of MCF-7 tumour per mouse. Tumour volumes were monitored weekly by caliper measurement of the length, width and height and were calculated using the formula for a semiellipsoid $\left(4 / 3 \pi r^{3} / 2\right)$. After 3 weeks, mice bearing tumours with volumes averaging $\sim 200 \mathrm{~mm}^{3}$ were randomised for treatment. Because of the variations in tumour and initial tumour growth, as well as the removal of mice for analysis at various time points, number of mice at each time point varied from experiment to experiment. The number of mice analysed is reported in the text.

\section{Chromatin immunoprecipitation}

Formaldehyde was added at a final concentration of $1 \%$ directly to cell culture media. Fixation proceeded at $22^{\circ} \mathrm{C}$ for $10 \mathrm{~min}$ and was stopped by the addition of glycine to a final concentration of $0.125 \mathrm{M}$. The cells were collected by centrifugation and rinsed in cold phosphate-buffered saline. The cell pellets were resuspended in swelling buffer $(10 \mathrm{mM}$ potassium acetate, $15 \mathrm{mM}$ magnesium acetate, $0.1 \mathrm{~m}$ Tris ( $\mathrm{pH} 7.6$ ), $0.5 \mathrm{~mm}$ phenylmethylsulfonyl fluoride and $100 \mathrm{ng}$ of leupeptin and aprotinin per $\mathrm{ml}$ ), incubated on ice for $20 \mathrm{~min}$, and then Dounce homogenised. The nuclei were collected by micro-centrifugation and then resuspended in sonication buffer ( $1 \%$ sodium dodecyl sulphate, $10 \mathrm{~mm}$ EDTA, $50 \mathrm{~mm}$ Tris- $\mathrm{HCl}$ ( $\mathrm{pH} 8.1$ ), $0.5 \mathrm{~mm}$ phenyl-methyl-sulfonyl fluoride, and $100 \mathrm{ng}$ of leupeptin and aprotinin per $\mathrm{ml}$ ) and incubated on ice for $10 \mathrm{~min}$. Before sonication, $0.1 \mathrm{~g}$ of glass beads (212-300 $\mu$ m diameter; Sigma) was added to each sample. The samples were sonicated on ice at setting 10 for 20 -s pulses to an average length of $\sim 1000 \mathrm{bp}$ and then micro-centrifuged. The chromatin solution was precleared with the addition of Staphylococcus aureus protein A-positive cells for $15 \mathrm{~min}$ at $4{ }^{\circ} \mathrm{C}$. Before use, the Staph A cells were blocked with $1 \mu \mathrm{g}$ of sheared herring sperm DNA per $\mu \mathrm{l}$ and $1 \mu \mathrm{g}$ of bovine serum albumin per $\mu \mathrm{l}$ for at least $4 \mathrm{~h}$ at $4{ }^{\circ} \mathrm{C}$. Precleared chromatin from $10^{7}$ cells was incubated with $1 \mu \mathrm{g}$ of affinity-purified rabbit polyclonal antibody or no antibody and rotated at $4{ }^{\circ} \mathrm{C}$ for $\sim 12-16 \mathrm{~h}$. p53 antibodies were used for immunoprecipitation and washing, and elution of immune complexes was carried out as previously described. Before the first wash, $20 \%$ of the supernatant from the reaction with no primary antibody for each time point was saved as total input chromatin and was processed with the eluted immunoprecipitates beginning at the cross-link reversal step. Cross-links were reversed by the addition of $\mathrm{NaCl}$ to a final concentration of $200 \mathrm{~mm}$, and RNA was removed by the addition of $10 \mu \mathrm{g}$ of RNase A per sample followed by incubation at $65^{\circ} \mathrm{C}$ for $4-5 \mathrm{~h}$. The samples were then precipitated at $-20^{\circ} \mathrm{C}$ overnight by the addition of 2.5 volumes of ethanol and then pelleted by microcentrifugation. The samples were resuspended in $100 \mu \mathrm{l}$ of TrisEDTA (pH 7.5), $25 \mu \mathrm{l}$ of $5 \times$ proteinase $\mathrm{K}$ buffer (1.25\% sodium dodecyl sulphate, $50 \mathrm{~mm}$ Tris (pH 7.5) and $25 \mathrm{~mm}$ EDTA) and $1.5 \mu \mathrm{l}$ of proteinase $\mathrm{K}$ (Boehringer Mannheim, Indianapolis, IN, USA) and incubated at $45^{\circ} \mathrm{C}$ for $2 \mathrm{~h}$. Samples were extracted with 
phenol-chloroform-isoamyl alcohol $(25: 24: 1)$ followed by extraction with chloroform-isoamyl alcohol and then precipitated with $1 / 10$ volume of $3 \mathrm{~m} \mathrm{NaOAc}(\mathrm{pH} 5.3), 5 \mu \mathrm{g}$ of glycogen and 2.5 volumes of ethanol. The pellets were collected by microcentrifugation, resuspended in $30 \mu \mathrm{lof} \mathrm{H}_{2} \mathrm{O}$ and analysed by PCR PCR amplification of genomic fragments containing TIGAR BS and TIGAR BS2 was performed with specific primers flanking the putative binding sites of TIGAR (BS1: $5^{\prime}$-GCTTCAGACGTATATAT AGA- $3^{\prime}$ and $5^{\prime}$-GGGGCTATTCTTGGTAGTAA- $3^{\prime}$, BS2: $5^{\prime}$-CGGCAG GTCTTAGATAGCTT- $3^{\prime}$ and $5^{\prime}$-GGCAGCCGGCATCAAAAACA-3').

\section{RESULTS}

p53 regulates TIGAR expression at low doses of UV and tamoxifen

As p53 downregulates glycolysis through TIGAR and upregulates oxidative phosphorylation through SCO2 (Matoba et al, 2006), we hypothesised that p53 might fail to antagonistically regulate glycolysis and oxidative phosphorylation under identical conditions of cellular stress. We first determined whether p53-mediated
A
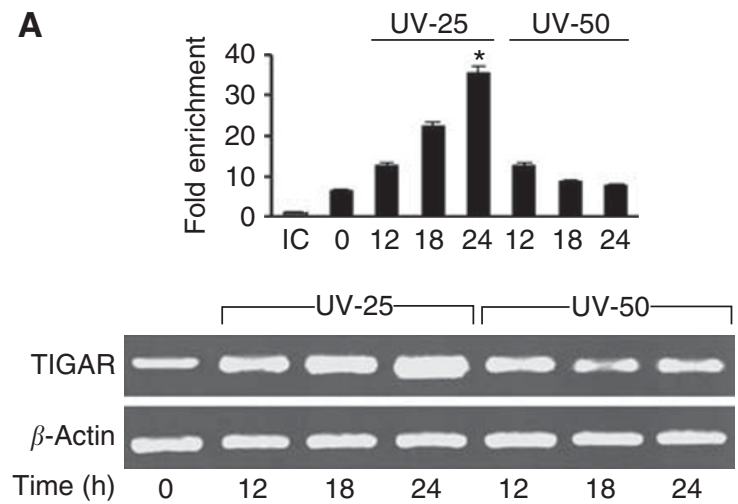

B
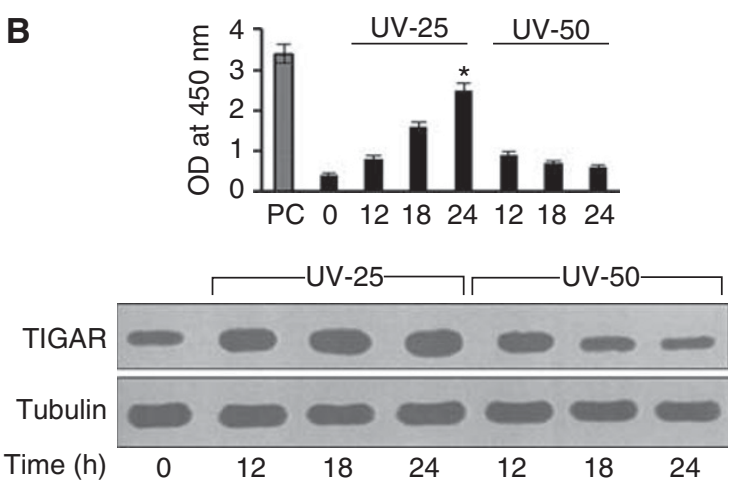
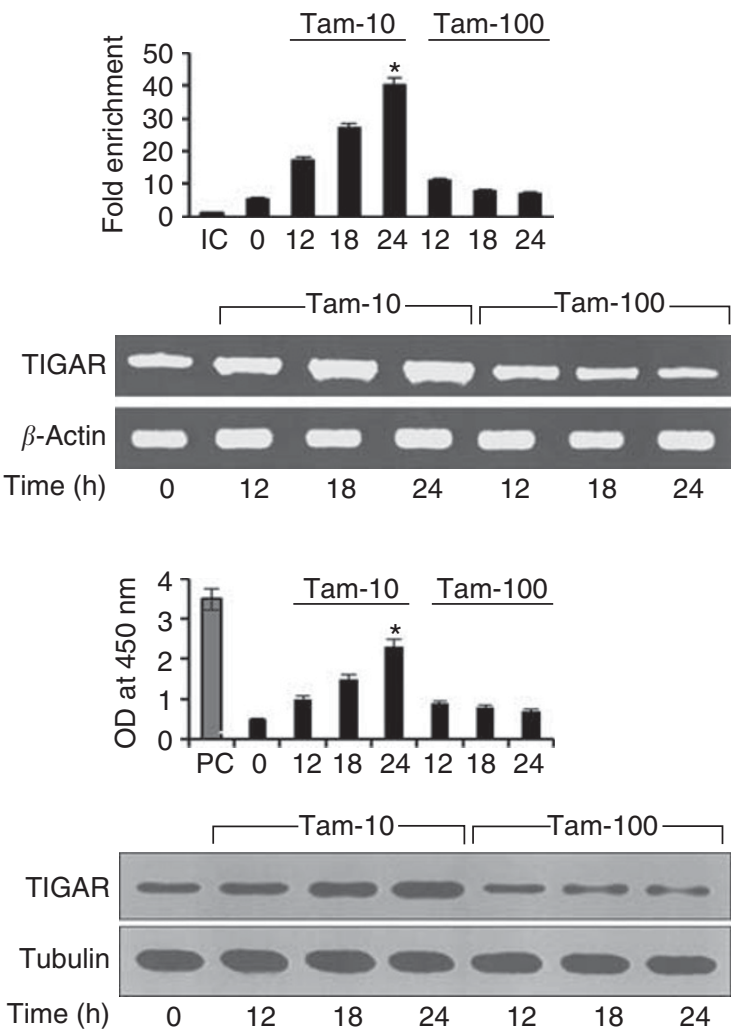

C

\begin{tabular}{|c|c|c|c|c|c|c|c|c|}
\hline & Control & UV-25 & UV-50 & cDNA & Control & Tam-10 & Tam-100 & cDNA \\
\hline TIGAR & $\longrightarrow$ & ens & - & & & 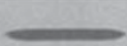 & & \\
\hline ubulin & & & & & & & & \\
\hline
\end{tabular}

D

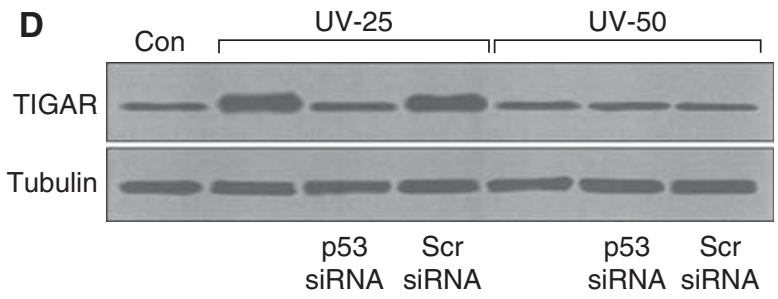

E

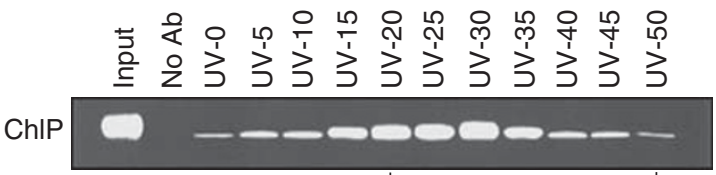

$\mathbf{F}$

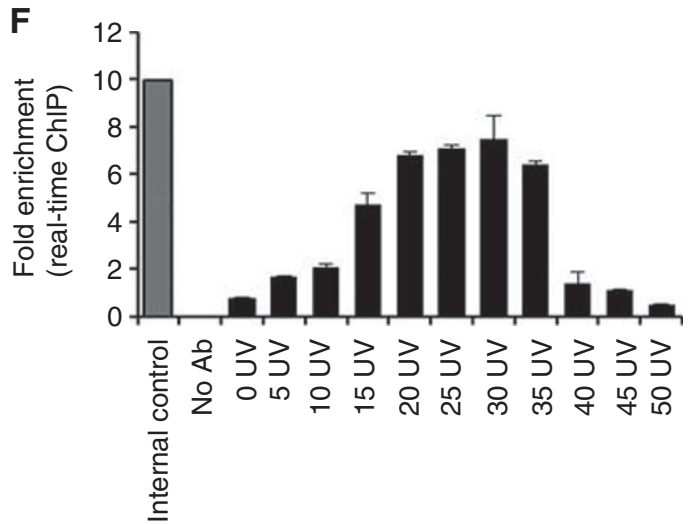


regulation of TIGAR is dependent upon the degree of cellular stress. TIGAR mRNA expression (Figure 1A) was analysed in KB cells treated with low $\left(25 \mathrm{~J} \mathrm{~cm}^{-2}\right)$ and high $\left(50 \mathrm{~J} \mathrm{~cm}^{-2}\right)$ doses of UV, and tamoxifen (10 and $100 \mathrm{~nm}$ ) (Tam-10 and Tam-100) in a time-dependent manner. KB cells were treated with UV (25 and $50 \mathrm{~J} \mathrm{~cm}^{-2}$ ) for $0 \mathrm{~h}$ (control), $12 \mathrm{~h}, 18 \mathrm{~h}$ and $24 \mathrm{~h}$. Following treatment the total mRNA of the cancer cells was extracted and used for real-time (quantitative) and reverse-transcriptase PCR analysis. The results of both qPCR and RT-PCR were similar and showed that UV-25 treatment resulted in progressive increase in TIGAR mRNA level from 0 to $24 \mathrm{~h}$ whereas UV-50 was unable to induce any significant increase in the TIGAR mRNA level from 0 to $24 \mathrm{~h}$. A similar effect of tamoxifen at a low dose $(10 \mathrm{~nm})$ and high dose (100 nM) was observed on the TIGAR mRNA expression in KB cells using both qPCR and RT-PCR (Figure 1A). KB cells were incubated with the two doses of tamoxifen for 12,18 or $24 \mathrm{~h}$. The results showed that Tam-10 was able to induce maximum expression of the TIGAR mRNA at $24 \mathrm{~h}$ time point. On the other hand, Tam-100 had no significant effect on TIGAR mRNA expression at 12,18 or $24 \mathrm{~h}$ time point. In conclusion, the TIGAR mRNA expression was five-fold higher at the low dose of UV and tamoxifen than in higher doses. Similarly, TIGAR protein expression was analysed in UV- and tamoxifentreated $\mathrm{KB}$ cells using quantitative in vivo ELISA and western blot techniques (Figure 1B). The results showed that only UV-25 and Tam-10 were effective in upregulating TIGAR protein expression at the $24 \mathrm{~h}$ time point, whereas UV-50 and Tam-100 were not effective in inducing the expression of TIGAR protein in KB cells. In conclusion, the TIGAR expression was four-fold higher in $\mathrm{KB}$ cells treated with low doses of UV and tamoxifen. Next, the role of UV and tamoxifen stress gradient in regulation of TIGAR was determined in the epithelial tissue of UV- and tamoxifen-treated Swiss albino mice (Figure 1C). After treatment of UV-25, UV-50, Tam-10 and Tam-100 for $24 \mathrm{~h}$ on the mice epithelial tissue, the tissue samples were collected and analysed for the expression of TIGAR protein expression using western blotting. The results showed that the TIGAR protein expression was high only at low doses of UV (UV-25) and tamoxifen (Tam-10). As TIGAR is an established transcriptional target of p53 (Bensaad et al, 2006), the role of p53 in the observed rise in TIGAR mRNA and protein level at low doses of UV and tamoxifen was important to be analysed. We observed whether the UV-25-induced increase in TIGAR mRNA and protein levels was p53 dependent by silencing $p 53$ gene using p53 siRNA in the treated KB cells (Figure 1D). The results showed that $\mathrm{p} 53$ silencing abolished UV-25-induced expression of TIGAR (lane 3; Figure 1D), scrambled siRNA of p53 served as a negative control (lane 4). Interestingly, $p 53$ gene silencing did not cause any significant change in the UV-50-induced p53 protein level (lane 6), suggesting that p53 might not transcriptionally regulate TIGAR gene at high doses of cellular stress. Luciferase assay was conducted to determine p53-mediated transcriptional regulation of TIGAR gene promoter during low doses of stress (Supplementary Figure S1). TIGAR gene promoter region with p53-response element (p53-RE) was cloned in a pGL3 vector and the construct was transfected in $\mathrm{KB}$ cell treated with increasing dose of UV for $24 \mathrm{~h}$. The results showed an increase in p53dependent luciferase activity only in KB cells that were treated with low doses of UV (Supplementary Figure S1). In the luciferase assay, p53 siRNA was used as the control to study the role of p53, and p53 scr siRNA was used as another control as shown in the figure. These data suggested that p53 transcriptionally regulates TIGAR gene promoter only in cancer cells subjected to low doses of cellular insult. The p53-mediated transcription at the TIGAR gene promoter was significantly reduced upon increasing the UV dose, suggesting that $\mathrm{p} 53$-mediated transcriptional regulation at TIGAR gene promoter is abolished at higher doses of cellular insult. As p53 mediates its transcriptional efficiency by directly binding to its REs in the promoter region of its downstream genes, we observed the direct binding of p53 at the TIGAR-RE in UV-treated (UV-0 to UV-50) KB cells using chromatin immunoprecipitation (ChIP). Analysis of p53 binding to p53 RE ( + 340 to +362 , BS2), as described by (Bensaad et al, 2006), at the TIGAR promoter using ChIP shows that p53 binds $>8$-fold to its RE in KB cells exposed to low dose of UV (Figure 1E). p53 showed very high binding to its RE at the TIGAR promoter in KB cells treated UV-20, UV-25, UV-30 and UV-35 (lanes 6-9), upon increasing the dose to $\geqslant \mathrm{UV}-40$ the binding between p53 and p53-TIGAR-RE showed significant decrease. The real-time ChIP experiment showed similar results where low doses of UV resulted in strong binding of p53 to its RE at the TIGAR promoter (Figure 1F). These data confirmed the fact that p53 specifically regulated TIGAR gene promoter exclusively in cancer cells subjected to low doses of cellular stress and at high doses p53-mediated regulation of TIGAR gene was abolished. As TIGAR is known to negatively regulate glycolysis we observed whether the TIGAR-mediated regulation of cellular glycolysis was also dependent upon the degree of cellular stress in cancer cells. The effect of altering TIGAR levels on the cellular glycolysis rate was studied. Glycolytic rates and TIGAR protein levels were determined in $\mathrm{KB}$ cells treated with different UV doses (Supplementary Figures S2A and B). The in vivo ELISA of TIGAR protein in the UV-treated $\mathrm{KB}$ cells showed that the expression of TIGAR protein increased between UV-5 to UV-35 exposure and then decreased between UV-35 and UV-50 exposure (Supplementary Figure S2A). The cellular glycolysis levels showed similar pattern where the glycolytic rates significantly dropped with increasing UV exposure from UV-5 to UV-35 and the

Figure I p53-mediated regulation of TIGAR occurs at low doses of cellular stress. (A) KB cells were treated with $25 \mathrm{~J} \mathrm{~cm}{ }^{-2}\left(\mathrm{UV}_{-}-25\right)$ or $50 \mathrm{~J} \mathrm{~cm}{ }^{-2}(\mathrm{UV}-50)$ of UV light for a period of $0,12,18$ and $24 \mathrm{~h}$. TIGAR mRNA expression was analysed using real-time PCR (bar graph) and RT-PCR. UV-25 exposure induced maximum increase in the TIGAR mRNA at $24 \mathrm{~h}$ of exposure, whereas UV-50 was not effective in upregulating TIGAR mRNA expression ( $n=5$ ). $\mathrm{KB}$ cells were treated with $10 \mathrm{nM}$ (Tam-10) or $100 \mathrm{nM}(\mathrm{Tam}-100)$ of tamoxifen for a period of $0,12,18$ and $24 \mathrm{~h}$, and the expression of TIGAR mRNA was analysed using real-time PCR (bar graph) and RT-PCR assay. Low dose of tamoxifen (Tam-10) for incubation period of $24 \mathrm{~h}$ was able to induce higher expression of TIGAR mRNA (lane 5; $n=5$; *represents significant difference between lanes 5 and $8, P<0.035$ ). (B) The expression of TIGAR protein in KB cells was analysed using in vivo ELISA (bar graph) and western blot. Similar to TIGAR mRNA expression, TIGAR protein was also upregulated with low doses of UV (UV-25) and tamoxifen (Tam-I0; $n=5$; * represents significant difference between lanes 5 and $8, P<0.04)$. (C) The dose-dependent expression of TIGAR protein was observed in vivo using Swiss albino mice. The skin tissue of the Swiss Albino mice was subjected to UV treatment and the expression of TIGAR protein was observed using western blot. Low doses of UV were again more effective in upregulating TIGAR protein. Similarly, low doses of tamoxifen were more capable of increasing TIGAR protein level in the mice $(n=5)$. (D) p53-mediated regulation of the expression of TIGAR at low and high doses of UV. TIGAR protein synthesis is abolished in KB cells where p53 gene was silenced using p53 si-RNA. p53 scrambled siRNA was used as control $(n=5)$. (E) p53 binds more to the TIGAR promoter in KB cells treated at low doses of UV. Chromatin immunoprecipitation showing p53 binding to its DBS on TIGAR promoter was conducted in KB cells treated with increasing doses of UV (UV-5 to UV-55). ChIP on TIGAR promoter showed that p53 binding was high at low doses of UV stress and this binding reduced with increase in the strength of UV exposure $(n=7)$ (*represents significant difference between lanes 7 and $13, P<0.02)$. (F) ChIP is repeated using real-time PCR. Results show that p53 binds to its RE at the TIGAR promoter only during low doses of cellular stress. 
glycolytic rates were higher with increasing dose As per the model p53 activates of UV exposure above UV-35 (Supplementary Figure S2B). The effect of TIGAR on the glycolytic rates was further studied by silencing TIGAR gene using TIGAR siRNA. The UVinduced alterations of the cellular glycolytic rate were abolished upon TIGAR gene silencing (Supplementary Figure S2B). These data suggested that the TIGAR-mediated regulation of cellular glycolysis occurs during the exposure to low doses of UV stress. As glycolysis regulates ATP synthesis, the effect of TIGAR on cellular ATP level was analysed. Low doses of UV upregulate TIGAR also reduced the ATP levels, whereas TIGAR gene silencing and exogenous addition of TIGAR cDNA significantly increased and reduced the cellular ATP level, respectively (Supplementary Figures S3A and B). Overall the results established that p53 binds to TIGAR promoter and activates TIGAR expression at low doses of UV and tamoxifen, and thus regulates the rate of glycolysis and ATP levels in cancer cells suffering from repairable stress-induced damage.

\section{TIGAR promotes p53-mediated cell-cycle arrest}

It is clear that p53 activates TIGAR gene expression only in cells suffering from low doses of genotoxic/cellular stress. At these doses of stress, p53 adopts the cell-cycle arrest effector response and facilitates the maintenance of genome integrity. We determined whether p53-mediated upregulation of TIGAR is related with the p53-mediated cell-cycle arrest in cancer cells (Figure 2A). The KB cells were treated with Tam-10 for $24 \mathrm{~h}$ and the cells were used to determine cell-cycle perturbations using flow cytometry. In control cells, the cell-cycle distribution curve showed $55 \%$ population in the G0-G1 phase, $18 \%$ population in the G2-M phase and $27 \%$ population in the $S$ phase of the cell cycle, and upon treatment with Tam-10 the cells were arrested in the G0-G1 phase (Figures 2A and B). To study the role of TIGAR in this G1-phase arrest, the TIGAR gene was silenced using TIGAR siRNA, which resulted in release of the cell-cycle arrest and decrease in the G0-G1 phase population from 86 to $67 \%$ (Figures $2 \mathrm{~A}$ and $\mathrm{B}$ ). Further, exogenous addition of TIGAR cDNA led to a strong G0G1 phase arrest with $92 \%$ cell population lying in this phase. These data suggested crucial role of TIGAR in inducing G1-phase arrest in cancer cells suffering from low doses of cellular stress. The role of p53 in TIGAR-induced cell-cycle arrest was observed by silencing p53 gene using p53 siRNA in tamoxifen-treated KB cells (Supplementary Figure S4). The results showed that upon p53 silencing the TIGAR protein level was significantly reduced (Supplementary Figure S4A) and the tamoxifen-mediated cellcycle arrest was abolished (Supplementary Figure S4B). The abolished cell-cycle arrest was restored upon ectopic addition of TIGAR protein using TIGAR cDNA (Supplementary Figure S4B). As TIGAR induced G1 arrest, the effect of TIGAR on cellular expression of genes involved in the regulation of cell-cycle arrest was observed. Western blot analysis of p21, p53, p27, p57, p16, ATM, ATR, BARCA1, CHEK2 and CDKN2A proteins in KB cells were performed to study the effect of TIGAR on their cellular expression levels (Figure 2C). The expressions of all the listed proteins were determined in normal KB cells (lane 1) and their protein levels were determined in Tam-10-treated KB cells (lane 2). The results showed that the expression of all the proteins involved in cell-cycle arrest was increased upon tamoxifen treatment. TIGAR gene was silenced to determine the role of TIGAR protein in tamoxifen-induced expression of the proteins involved in cellcycle arrest (lane 3). Interestingly, the tamoxifen-induced increase in cell-cycle arrest genes was abolished upon TIGAR gene silencing. As TIGAR cDNA exogenous addition was able to induce G1-phase arrest, the role of TIGAR protein in regulation of the expression of cell-cycle arrest genes was observed in KB cells (lane 4). Exogenous addition of TIGAR cDNA resulted in a significant increase in the expression of the cell-cycle arrest genes. It was interesting to observe that TIGAR gene silencing or TIGAR cDNA addition had no impact on the expression of p53 protein in the cancer cells. The cDNA constructs of all the cell-cycle arrest proteins were transfected as positive controls (lane 5). Further, the effect of TIGAR expression on the proteins involved in cell-cycle progression including the members of the $\mathrm{RB}$ protein pathway and its regulatory cyclins (Cyclins D and E) and the CDKs (CDK2, CDK4 and CDK5), p53 and TIGAR was also studied (Figure 2D). Control cells showed basal expression level of these proteins (lane 1) and upon tamoxifen treatment the expression of these genes was significantly reduced (lane 2 ). It was previously shown that tamoxifen induces significant decrease in the expression of Cyclin $\mathrm{D}$, CDK2, CDK4, CDK6, E2F1, RB and Cyclin E during G1-phase arrest (Brady et al, 2005; Masamha and Benbrook, 2009; Bryant et al, 2010). Further, the role of TIGAR in the tamoxifenmediated decrease in cell-cycle genes was observed by silencing TIGAR gene that abolished the tamoxifen-mediated repression of these proteins (Figure 2C, lane 3). These data suggested that TIGAR might have a role in the regulation of the expression of these genes involved in cell-cycle progression. To check the efficiency and specificity of TIGAR siRNA a scrambled siRNA of TIGAR was used as control that had no effect on the expression of these proteins (lane 4). p21, which is a known inhibitor of the cellcycle progression, was silenced as control to study its effect on the expression of these genes (lane 5). p21 silencing did not alter the expression of these genes suggesting that the expression of these proteins were not influenced by cellular p21 levels. The exogenous TIGAR expression by transfecting TIGAR cDNA was also able to reduce the expression of these proteins both in presence and absence of p21 (Figure 2c, lanes 6 and 7). These data suggested that TIGAR has a crucial role in regulating the expression levels of the genes involved in cell-cycle progression and this effect is independent of the status of the known cell-cycle arrest protein that is p21. Overall, the results suggested a major role of TIGAR in halting cell-cycle progression of rapidly dividing cancer cells at the G1 phase and in the regulation of cell-cycle progression at genetic level.

To study the role of TIGAR in regulation of the expression of genes involved in cell-cycle progression, as well as cell-cycle arrest, we conducted real-time PCR analysis of 85 genes involved in this cellular event in both MCF-7 cancer cells (Figure 3A) and MCF-7 tumour xenografts (Figure $3 \mathrm{~B}$ ) using the real-time PCR array kit PAHS-020 from SA-Biosciences (Valencia, CA, USA). In MCF-7 cells represents the basal expression level of genes involved in arresting the cell-cycle progression or supporting the progression of cell cycle are shown for MCF-7 cells (Figure 3A; lane 3) and MCF-7 tumour (Figure 3B; lane 1). Upon addition of tamoxifen, at a low dose that results in cell-cycle arrest, all the genes involved in cell-cycle arrest were upregulated and the gene sets involved in cell-cycle progression were downregulated (Figure 3A; lane 1). The results showed that TIGAR regulates the expression of cell-cycle genes both in MCF-7 cells and MCF-7 tumour xenografts. Upon silencing TIGAR gene using TIGAR siRNA in tamoxifen-treated MCF-7 cells, the expression of these genes were altered and there was significant increase in the genes involved in cell-cycle progression and a decrease in the genes involved in cell-cycle arrest (Figure 3A; lane 2). Finally, the exogenous addition of TIGAR cDNA led to significant increase in the genes involved in cell-cycle arrest and a decrease in the expression of genes involved in cell-cycle progression (Figure 3; lane 4). Similarly in MCF-7 tumour xenografts, most of the genes involved in cell-cycle arrest were low in their expression profile whereas the genes involved in cell-cycle progression were higher in their expression (lane 1). Upon exogenous addition of TIGAR cDNA in the tumour tissue using in vivo transfection kit the expression of the genes involved in cell-cycle arrest was significantly increased and the expression of the genes involved in cell-cycle progression was significantly 

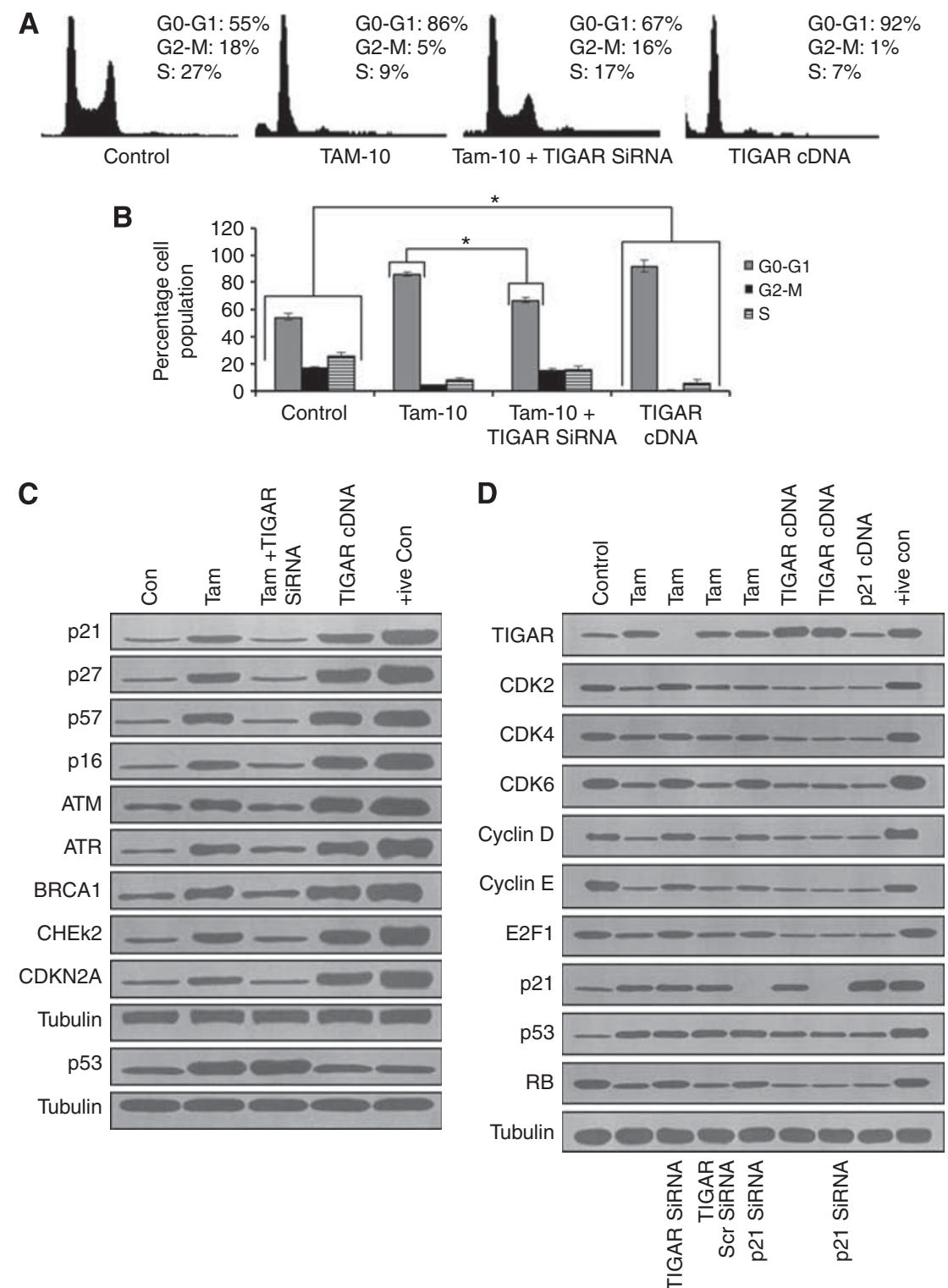

Figure 2 TIGAR promotes p53-mediated cell-cycle arrest in GI phase. (A) Cell-cycle analysis of KB cells was conducted using flow cytometry. The data show that tamoxifen-induced GI-phase arrest is TIGAR dependent as TIGAR siRNA released the GI arrest. Exogenous addition of TIGAR cDNA induced GI arrest in KB cells $(n=10)$. (B) Quantitative results of the cell-cycle distribution curve depicting the role of TIGAR protein in mediating GI-phase of the cell-cycle arrest $(n=10$, s.d, ANOVA) (*represents significant difference between control and TIGAR cDNA; $P<0.032)(*$ represents significant difference between Tam-IO and Tam-10 + TIGAR siRNA; P<0.045). (C) TIGAR increases the expression of proteins involved in cell-cycle arrest. Western blot analysis of cell-cycle arrest proteins (p21, p27, p57, p 16, ATM, ATR, BRCAI, CHEK2, CDKNIA and p53) shows a significant increase in their expression upon tamoxifen treatment (lane 2). Upon silencing TIGAR gene using TIGAR siRNA, the expression of these proteins was significantly reduced (lane 3). Exogenous addition of $2 \mu \mathrm{g}$ of TIGAR cDNA to KB cells led to significant increase in the expression of proteins involved in cell-cycle arrest. Tubulin serves as loading control and cDNA of all the proteins were transfected in KB cells to serve as positive control. (D) TIGAR inhibits the expression of the members of cyclin-CDK complex. The expression of the proteins involved in constitution of the cyclin-CDK complex that mediates RB phosphorylation was observed in KB cells. The data show that TIGAR reduces the expression of the members of cyclin-CDK complex and E2FI transcription factor. These proteins are required for the entry of cells in the $S$ phase of cell cycle. Tamoxifen treatment reduces the expression of these proteins (lane 2) and TIGAR gene silencing again increases their expression. Exogenous addition of TIGAR cDNA induces significant decrease in the expression of these proteins (lane 6). The TIGARmediated effect on the expression level of these genes is independent of p2I as p2I siRNA has no effect on their expression. Tubulin, p2I siRNA, p2I cDNA, TIGAR scrambled siRNA and the cDNA of the cell-cycle proteins serves as controls.

decreased (Figure 3B; lane 2). Overall, the gene expression data suggest the role of TIGAR in the regulation of cell cycle of cancer cells at the genetic level.

\section{TIGAR mediates de-phosphorylation of RB and stabilises RB-E2F1 complex}

The RB protein is phosphorylated by Cyclin D-cdk4 and Cyclin $\mathrm{E}$-cdk2 complexes (Mittnacht, 1998) and this is required by cancer cells to progress from G1 phase to $S$ phase of cell cycle (Duronio, 2004). RB phosphorylation breaks RB-E2F1 protein complex, resulting in release of E2F1 protein and transcription of the E2F1responsive genes, which are required for entry into $S$ phase (Nevins, 1992). The relation between TIGAR-induced G1 arrest and $\mathrm{RB}$ phosphorylation was analysed by immunoprecipitating phosphorylated $\mathrm{RB}$ in $\mathrm{KB}$ cells subjected to low doses of cellular stress, using phospho-RB antibody (Figure 4A). In normal $\mathrm{KB}$ cells, the $\mathrm{RB}$ protein is hyper-phosphorylated (lane 2) and 


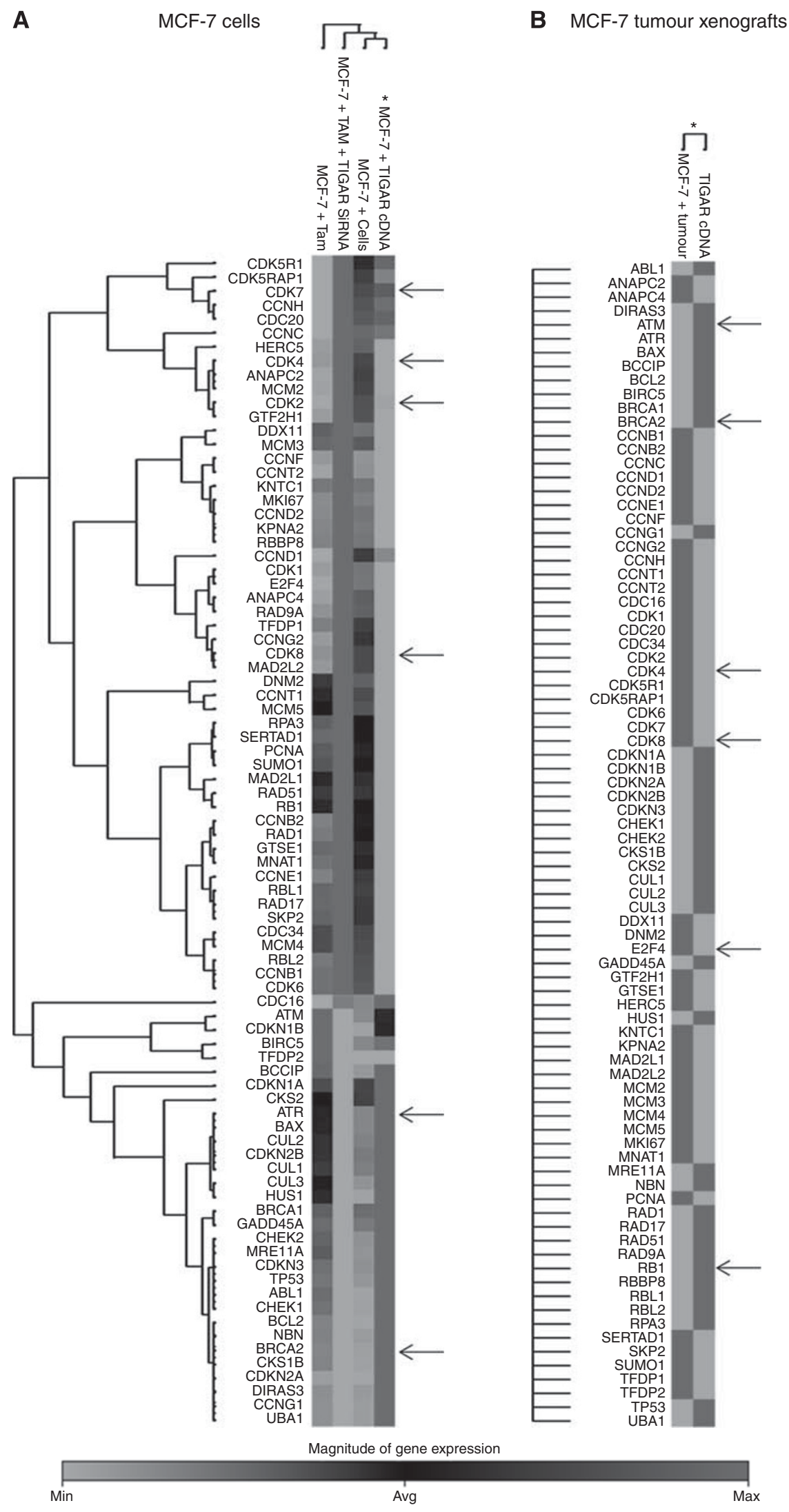


tamoxifen-treatment abolished the RB phosphorylation and induces $\mathrm{G1}$ arrest in $\mathrm{KB}$ cells (lane 3). However, silencing of TIGAR gene in treated cells increases the phosphorylation of $\mathrm{RB}$ protein (Figure 4A, lane 4). These data suggested that TIGAR might promote cell-cycle arrest by inducing hypo-phosphorylation of $\mathrm{RB}$ protein in cancer cells. The exogenous addition of TIGAR cDNA also induces de-phosphorylation of RB protein (Figure 4A, lane 6). Input and $p 21$ gene silencing using p21 siRNA were used as positive controls. These data show that TIGAR-mediated G1 arrest is mediated by de-phosphorylation of $\mathrm{RB}$ protein by downregulating the expression of the members of cyclin-Cdk complex. $\mathrm{RB}$ phosphorylation releases E2F1 that is essential for synthesis of protein factors involved in the entry of the cell cycle in $S$ phase. Next we determined whether TIGAR regulates the stability of $\mathrm{RB}-\mathrm{E} 2 \mathrm{~F} 1$ protein complex. Coimmunoprecipitation using anti-RB and anti-E2F1 antibodies showed that TIGAR expression stabilised the complex between RB and E2F1 (Figure 4B). The RB-E2F1complex was broken in $\mathrm{KB}$ cells undergoing normal cell-cycle progression (Figure 4B, lane 1). Exogenous addition of p21 cDNA stabilised the $\mathrm{RB}-\mathrm{E} 2 \mathrm{~F} 1$ complex (Figure $4 \mathrm{~B}$, lane 4 ). As TIGAR is proposed to induce cell-cycle arrest, the effect of TIGAR on the stability of RB-E2F1 complex was analysed. TIGAR was found to stabilise the RB-E2F1 complex and this TIGAR-mediated regulation of RB-E2F1 complex was independent of p21 (Figure 4B, lanes 3, 5). As TIGAR induced $\mathrm{RB}$ de-phosphorylation and inhibited the release of E2F1 from its complex with RB protein, E2F1 could not promote the entry of cells into $S$ phase of cell cycle. Thus, we establish that TIGAR induces p53-mediated cell-cycle arrest by negatively regulating the members of cyclin-Cdk complexes resulting in de-phosphorylation of RB and stabilisation of RB-E2F1 complex. Next, we analysed the role of TIGAR in tamoxifen-mediated tumour death in MCF-7, HCT p53 $(+/+)$, HCT p53 $(-/-)$ and A-431 tumour xenografts. All the tumour xenografts grown on the hind leg region of nude mice were transfected with TIGAR cDNA and treated with tamoxifen for 1 month. The results showed that combination of TIGAR cDNA and tamoxifen caused significant tumour regression (Figure $4 \mathrm{C}$ ).

\section{DISCUSSION}

The effect of TIGAR on cell survival was proposed to be cell- and context-dependent (Bensaad et al, 2006). Our data suggest that TIGAR falls into the group of genes that are activated by low levels of stress and has a key role in the tumour-suppressor function of p53. Interestingly, the switch from p53-induced cell-cycle arrest to apoptosis following prolonged stress is associated with a decrease in expression of both TIGAR and $\mathrm{p} 21^{\mathrm{WAF} 1 / \mathrm{CIP} 1}$, suggesting that the induction of the apoptotic response may reflect upon the loss of protection by these $\mathrm{p} 53$-inducible survival signals.

The progression of the cell cycle from quiescence to mitosis depends on the sequential expression of cyclins, which then interact with and activate specific CDK (Griffin et al, 2003). Exposure to the cell-arrest drugs causes increase in p21, p27 whereas Cyclin E-CDK2 remains inactive (Hu et al, 2001; Law et al,
2002), RB remains hypo-phosphorylated and restrains the activity of the E2F1 transcription factor (Zhang et al, 1999). The proproliferative E2F1-responsive genes are therefore not transcribed, and the cell remains trapped in G1 phase. We have also shown that the exogenous expression of TIGAR mediated hypo-phosphorylation of $\mathrm{RB}$ protein and stabilisation of the RB-E2F1 complex resulting in G1 arrest. These data suggest that TIGAR functions in a manner similar to p21 and other cyclin-Cdk inhibitors to induce p53mediated cell-cycle arrest.

In present study, we have shown that TIGAR is recruited by $\mathrm{p} 53$ to induce cell-cycle arrest in cancer cells undergoing mild cellular and genotoxic stress. The TIGAR-mediated G1 arrest is independent of p21 and is probably linked to its ability to regulate cellular glycolysis. TIGAR significantly reduced the cellular ATP level. TIGAR negatively regulated the expression of the proteins involved in the cyclin-Cdk complex, especially the expression of Cyclin D, Cyclin E, Cdk2, Cdk4 and Cdk6 is found to be very low. TIGARmediated inhibition of the members of the cyclin-Cdk complex resulted in de-phosphorylation of $\mathrm{RB}$ protein that led to stabilisation of the RB-E2F1 complex and G1-phase arrest. Thus, our results establish TIGAR as a cellular marker responsible for G1-phase arrest in cancer cells. The present data show that the ectopic expression of TIGAR cDNA results in cell-cycle arrest and TIGAR gene silencing in tamoxifen-treated $\mathrm{KB}$ cells abolishes tamoxifen-induced G1 arrest. However, it is important to understand that TIGAR-mediated cell-cycle arrest is not direct as TIGAR protein is a phosphatase of fructose-2,6-biphosphate and does not directly participate in the cell-cycle machinery. However, our data show that TIGAR regulates the cellular ATP levels in cancer cells exposed to low doses of cellular stress. Entry into the cell cycle requires energy in the form of ATP for the execution of a number of regulatory and metabolic events. Protein synthesis consumes large amounts of cellular energy and is required for entry into $S$ phase (Brooks, 1977; Herzig et al, 2000). Inhibition of the mitochondrial respiratory function inhibits progression to $\mathrm{G} 1$ in parallel with a reduction in cellular ATP (Sweet and Singh, 1995). Synthesis of protein involved in cell-cycle progression (Herzig et al, 2000) and degradation (Varshavsky, 1997) as well as the de-polymerisation of the microtubular network during interphase (Herzig et al, 2000) all depend upon the intracellular ATP concentration. ATP has also been implicated in the regulation of CDKs, which in turn control cell proliferation (Sheaff et al, 1997). Thus, by reducing cellular ATP levels in cancer cells exposed to low doses of stress TIGAR could function as the connecting network between ATP regulation and cell-cycle arrest. Mouysset et al, 2008 showed the importance of ATP hydrolysis in DNA replication and cell-cycle progression and established that the cellcycle progression requires the ATPase CDC- $48^{\mathrm{UFD} 1 / \mathrm{NPL} 4}$ complex for efficient DNA replication. Previously another study similar to the role of TIGAR and its downstream ATP regulation in cell-cycle arrest has been reported with gene encoding cytochrome oxidase subunit Va (Mandal et al, 2005). It is reported that metabolic status of the cell exerts a direct control over cell-cycle checkpoints and expression of genes involved in cell-cycle regulation (Mandal et al, 2005). In case of TIGAR overexpression, there is also a significant

Figure 3 TIGAR increases cell-cycle arrest genes and decreases cell-cycle progression gene expression in MCF-7 cells and MCF-7 tumour xenografts. The mRNA expression of 85 genes involved in cell-cycle arrest and progression were analysed in MCF-7 cancer cells and MCF-7 tumour xenografts using the PCR array kit (PAHS-020) from SA-Biosciences. (A) The basal expression of all the genes is represented in lane 3. Upon tamoxifen treatment, the genes involved in cell-cycle arrest were overexpressed and a decrease in the genes involved in cell-cycle progression is observed (lane I). Silencing of TIGAR gene in tamoxifen-treated cells increases the expression of cell-cycle progression genes and caused a decrease in the expression of arrest related genes (lane 2). Exogenous addition of TIGAR cDNA leads to increase in the expression of genes involved in cell-cycle arrest and a decrease in the genes involved in cellcycle progression (lane 4); ( $n=7$; *represents significant difference between lanes 3 and 4; $P<0.02$ ). (B) In MCF-7 tumour xenografts, the expression of genes involved in cell proliferation and cell-cycle progression is high (lanel). Upon addition of TIGAR cDNA in tumour tissue using in vivo transfection kit the expression of genes involved in cell-cycle arrest is high and the expression of genes involved in cell-cycle progression is low (lane2)); $(n=7$; represents significant difference between lanes I and 2; $P<0.01$ ). 
A

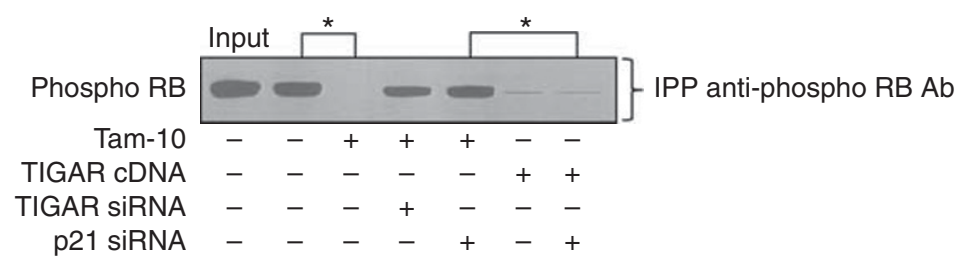

B
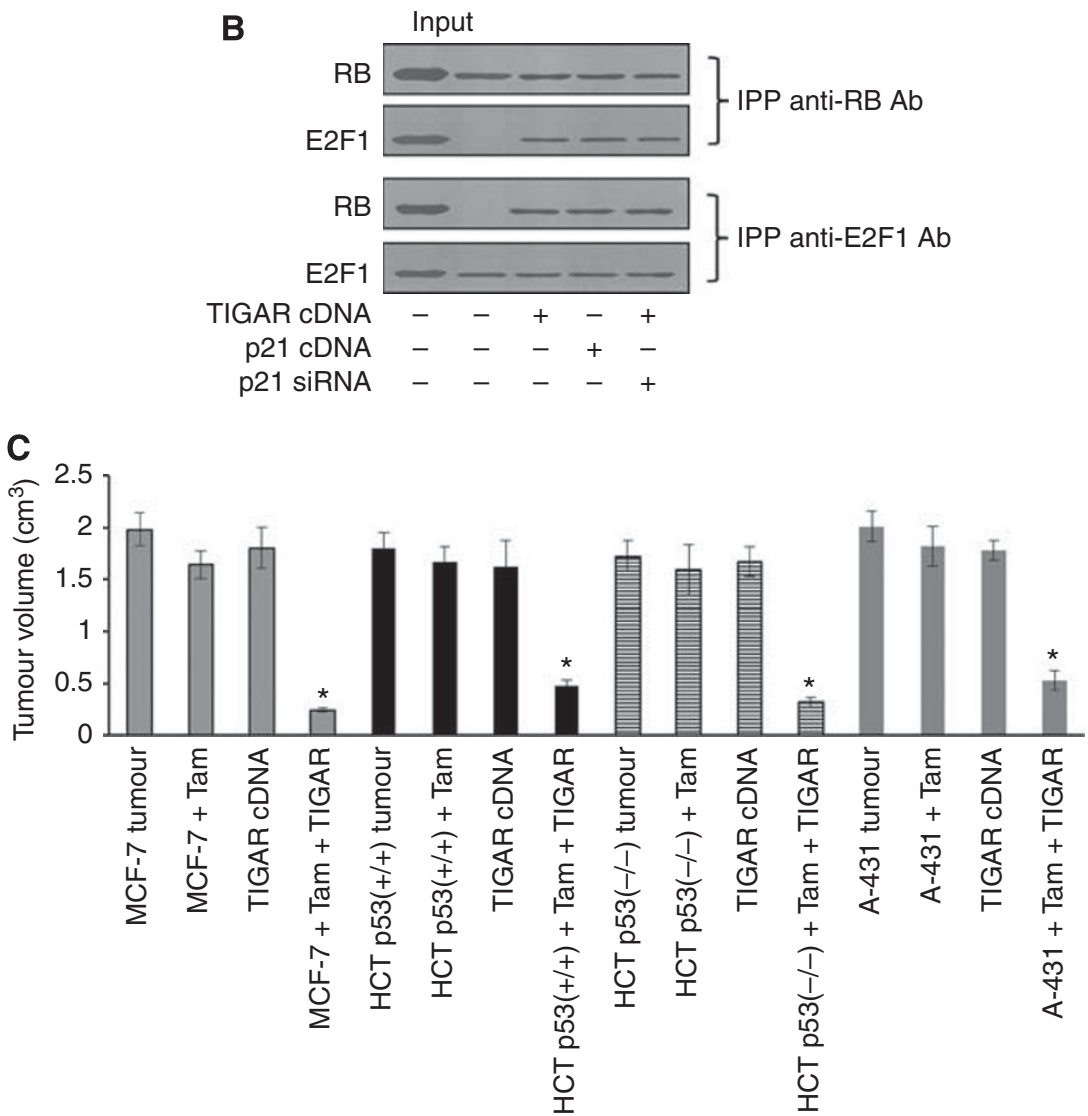

Figure 4 TIGAR mediates de-phosphorylation of RB protein. (A) The phosphorylation of RB protein was analysed using immunoprecipitation with phospho-RB antibody. Tamoxifen treatment leads to hypo-phosphorylation of RB protein (lane 3). Upon silencing TIGAR genes in tamoxifen-treated KB cells, the RB protein attains its hyper-phosphorylated status (lane 4). Addition of TIGAR CDNA results in hypo-phosphorylation of RB protein (lane 6). The effect of TIGAR on RB phosphorylation is independent of $\mathrm{p} 2 \mathrm{I}$ (lane 7). TIGAR expression significantly reduces the phosphorylation of RB protein (*represents significant difference between lanes 2 and 3; $P<$ than 0.0 I) (*represents significant difference between lanes 5 and $7 ; P<0.0 I$ ). (B) TIGAR inhibits the dissociation of the RBI-E2FI complex. Coimmunoprecipitation was conducted in KB cells using anti-RBI and anti-E2FI antibodies to analyse the effect of TIGAR expression on the stability of their complex. Exogenous addition of TIGAR cDNA stabilises the complex between RBI and E2FI transcription factor resulting in GI-phase arrest (lane 3); the effect of TIGAR protein on RB-E2FI binding is independent of the p2I status in cancer cells (lanes 4 and 5; $n=5$ ). (C) MCF-7, HCT p53 $(+/+)$ and HCT p53 $(-/-)$ tumours were grown on the hind leg region of Balb-c nude mice. The tumour volumes were measured in untreated, tamoxifen-treated, TIGAR cDNA-treated and tamoxifen + TIGAR cDNA-treated mice. Tamoxifen induces $25 \%$ tumour regression and TIGAR cDNA alone is unable to induce significant reduction in tumour volume. Tamoxifen + TIGAR cDNA treatment causes significant tumour regression. The representative images of tamoxifen treatment (left) and tamoxifen + TIGAR cDNA (right) show the respective tumour regression. This study was repeated on 12 animals in each group and $n=7$ (*represents significant difference between lanes ( $I-3$ ) with lane 4 for each group); $P<0.02$ for all the four tumour types).

increase in the expression of genes involved in cell-cycle arrest and a significant decrease in the expression of genes involved in cellcycle progression is seen. A mutation named tenured (tend), in a gene encoding cytochrome oxidase subunit $\mathrm{Va}$, causes a drop in intracellular ATP to levels sufficient to maintain cell survival, growth and differentiation, but not to enable progression through the cell cycle. The mutation in this gene led to activation of specific pathway involving AMPK and p53, which causes elimination of Cyclin E via an indirect pathway, resulting in cell-cycle arrest (Mandal et al, 2005). TIGAR protein also works downstream of p53 signalling and is involved in an indirect pathway of RB hypophosphorylation and G1-phase arrest. Thus, in multiple systems, the cellular ATP levels have a direct and specific role in enforcing a G1-S phase cell-cycle arrest during periods of energy deprivation. It is logical to believe that TIGAR-mediated decrease in cellular ATP levels led to indirect activation of G1-phase cell-cycle arrest and further led to TIGAR-mediated regulation of genes involved in cell-cycle arrest and progression. In the present study, we established that TIGAR induces hypo-phosphorylation of $\mathrm{RB}$ protein and stabilises RB-E2F1 complex resulting in the G1-phase 


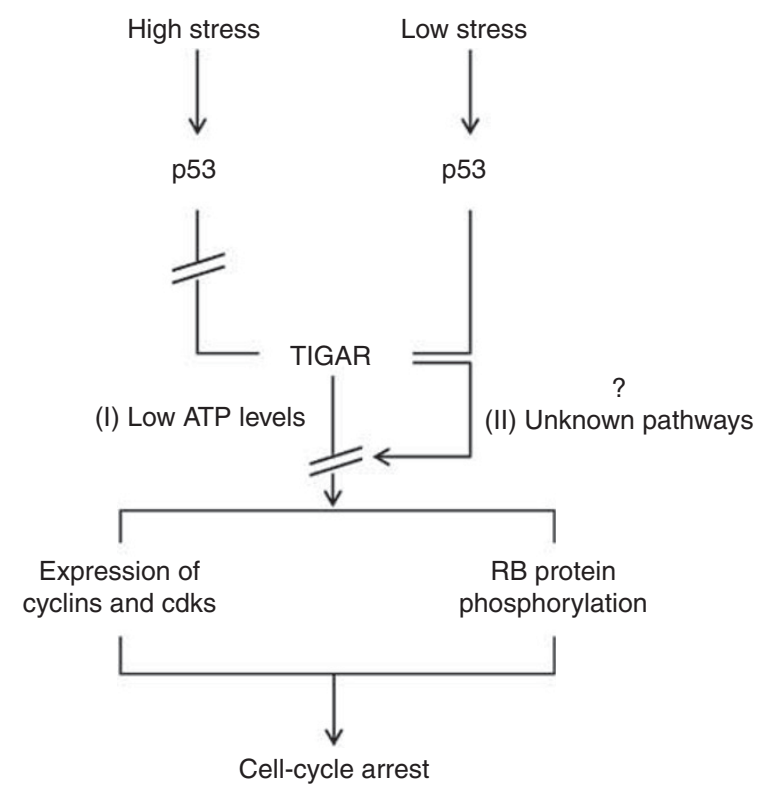

Figure 5 A model depicting the mechanism of TIGAR-mediated cellcycle arrest in cancer cells. p53 is unable to transcriptionally upregulate TIGAR protein in cells experiencing high doses of cellular stress and p53-dependent overproduction of TIGAR is observed in cells experiencing low doses of cellular stress. TIGAR protein decreases the expression of cyclins and cdks involved in cell-cycle progression and mediates hypophosphorylation of RB protein via (I) regulation of cellular ATP levels and (II) other unknown cellular pathways. The alterations in the expression of cyclins and cdks and hypo-phosphorylation of RB protein results in TIGAR-mediated cell-cycle arrest.

arrest. This observation also appears to be downstream of the TIGAR-mediated regulation of cellular ATP content. The role of ATP in the regulation of phosphorylation of cellular proteins in general is established (Viticchi et al, 1996; Korzeniewski, 2006). Previously it was shown that the ratio of various adenylate nucleotides indicates the metabolic condition of a cell, which in turn correlates with the ability of ATP to bring about phosphorylation of proteins. It has been shown that AMP is sensitive to metabolic stress as its levels increase rapidly upon administration of ischaemia. During ischaemia the levels of phosphorylation of proteins within a cell are significantly reduced. In the two separate investigations, phosphorylation levels of proteins decreased by about 4-14 times after a 10-min ischaemic stress (Thalmann et al, 1978; Thalmann et al, 1982), demonstrating that the phosphorylation event is closely associated with the relative abundance of ATP in a cell. The present results suggest towards a general phenomenon that decrease in ATP by interfering in the energygenerating processes of glycolysis or OXPHOS, for example, by proteins that affect the glycolysis intermediates, can induce a general state of decreased phosphorylation in a cell. In light of increasing evidence of tumour-suppressive role of genes that coordinate metabolism and prevent its dysregulation, this study may indicate a general relation of ATP levels in coordinating signalling. Similarly Kim et al, 2003 showed a close link between intracellular ATP concentrations and CDK4/Cyclin D1 activity and demonstrated existence of high association constant $\left(K_{\mathrm{m}}\right)$ of CDK4/Cyclin D1 for ATP in comparison to other CDKs. CDK4/ cyclin $\mathrm{D} 1$ complex is known to cause the phosphorylation of RB protein. Thus, it can be speculated that decreased intracellular ATP concentrations may result in reduced phosphorylation of $\mathrm{RB}$ protein by CDK4/cyclin-D1 and thus resulting in cell-cycle arrest. The TIGAR-mediated hypo-phosphorylation of $\mathrm{RB}$ protein can be the result of a general phenomenon where the phosphorylation status of many proteins gets affected in the cellular context where the ATP levels are diminishing. Thus, TIGAR-mediated regulation of ATP levels might control RB phosphorylation status and ultimately cell-cycle arrest.

It is also interesting to observe that although TIGAR induces more than 90\% G1-phase arrest but it does not directly involve itself in this phenomenon, and instead induced an indirect cell-cycle arrest. In past a variety of proteins in the cellular system are known to induce indirect cell-cycle arrest and it is now established that cell-cycle arrest may be brought about in ways other than the direct modification of the cell-cycle proteins. The regulation of mRNA stability by Akt/mTOR and MAPK/MAP kinase-interacting kinase-1 (MNK1) is one indirect way that increases the mRNA stability by phosphorylation of the eukaryotic mRNA cap-binding protein elongation factor (eIF4E) at its $\operatorname{Ser}^{209}$ residue (Ellederova et $a l, 2008)$. It has been recently shown that excessive phosphorylation of eIF4E by MNK1 causes increased proliferation in central nervous system lymphoma patients and an MNK1 inhibitor decreased Cyclin D1 levels and proliferation possibly by affecting mRNA stability (Muta et al, 2011). Another instance where cellcycle arrest is observed via an indirect mechanism was shown in endometrial carcinoma cells where induction of PTEN, a phosphatase that negatively regulates phospho-inositide 3-kinase pathway, decreased the level of Cyclin D3 and a concomitant increase in p27-CDK2 amount causing a cell-cycle arrest in G1 phase. Notably, the levels of known G1 inhibitors remained unchanged (Zhu et al, 2001). Another research reported that ARF (Alternative Reading Frame) tumour suppressor can overcome the effects of increased Cyclin A and Cdk2-dependent kinases to execute a p21-independent cell-cycle arrest (Modestou et al, 2001). Ubiquitin-mediated degradation of cyclin D1 under hypoxia in a p21-independent manner was observed as a downstream effect of ROS signalling in HCT116 cell lines (Lim et al, 2008). Further genistein-induced activation of kinases Myt-1 and Wee-1 results in cell-cycle arrest and both these kinases do not participate in cellcycle machinery (Touny and Banerjee, 2006). Taken together, these reports clearly demonstrate that execution of cell-cycle arrest does not require the direct interplay of cyclins, CDKs and CDKinhibitors and that this indirect arrest may not restricted to any specific phase of the cell cycle. Thus, we conclude that TIGAR promotes indirect cell-cycle arrest in cancer cell suffering from low and repairable doses of cellular stress by regulating ATP levels and modulation of the RB-E2F1 pathway. A model has been proposed (Figure 5) to explain the mechanism of the TIGAR-mediated cellcycle arrest. As per the model p53 activates TIGAR gene upregulation only in cancer cells exposed to low doses of UV stress. TIGAR gene activation inhibits the expression of genes involved in cell-cycle progression and inhibits phosphorylation of $\mathrm{RB}$ protein. TIGAR protein regulates this step by (I) regulation of the cellular ATP levels or (II) via some unknown cellular mechanism. Thus, TIGAR upregulation results in G1-phase cellcycle arrest in cancer cells suffering from repairable doses of cellular stress. Further, we propose the possibility of combinatorial therapy where the TIGAR-mediated cell-cycle arrest can be used in combination with therapeutic drugs to achieve higher apoptosis in aggressive cancer forms.

\section{ACKNOWLEDGEMENTS}

We thank UGC 'capacity build up fund' and NIH RO1 grant- NIH EB004031 for supporting us financially. We also thank Dr Shally Awasthi (Faculty Incharge Research Cell, CSMMU), Mrs Gizal Fatima, Mr Sahil Chaudhary and Mr Kartik Gupta for their research support.

Supplementary Information accompanies the paper on British Journal of Cancer website (http://www.nature.com/bjc) 


\section{REFERENCES}

Adams PD, Kaelin Jr WG (1995) Transcriptional control by E2F. Semin Cancer Biol 6: 99-108

Bensaad K, Tsuruta A, Selak MA, Vidal MN, Nakano K, Bartrons R, Gottlieb E, Vousden KH (2006) TIGAR, a p53-inducible regulator of glycolysis and apoptosis. Cell 126: 107-120

Brady G, Boggan L, Bowie A, O'Neill LA (2005) Schlafen-1 causes a cell cycle arrest by inhibiting induction of cyclin D1. J Biol Chem 280: 30723-30734

Brooks RF (1977) Continuous protein synthesis is required to maintain the probability of entry into S phase. Cell 12: 311-317

Bryant CS, Kumar S, Chamala S, Shah J, Pal J, Haider M, Seward S, Qazi AM, Morris R, Semaan A, Shammas MA, Steffes C, Potti RB, Prasad M, Weaver DW, Batchu RB (2010) Sulforaphane induces cell cycle arrest by protecting RB-E2F-1 complex in epithelial ovarian cancer cells. Mol Cancer 9: 47

Claudio PP, Howard CM, Fu Y, Cinti C, Califano L, Micheli P, Mercer EW, Caputi M, Giordano A (2000) Mutations in the retinoblastoma-related gene RB2/p130 in primary nasopharyngeal carcinoma. Cancer Res 60: $8-12$

De Luca A, MacLachlan TK, Bagella L, Dean C, Howard CM, Claudio PP, Baldi A, Khalili K, Giordano A (1997) A unique domain of pRb2/p130 acts as an inhibitor of Cdk2 kinase activity. J Biol Chem 272: 20971-20974

Dowdy SF, Hinds PW, Louie K, Reed SI, Arnold A, Weinberg RA (1993) Physical interaction of the retinoblastoma protein with human D cyclins. Cell 73: 499-511

Duronio RJ (2004) A breath of fresh air for cyclin D/Cdk4: triggering growth via Hph. Dev Cell 6: 163-164

Ellederova Z, Cais O, Susor A, Uhlirova K, Kovarova H, Jelinkova L, Tomek W, Kubelka M (2008) ERK1/2 map kinase metabolic pathway is responsible for phosphorylation of translation initiation factor eIF4E during in vitro maturation of pig oocytes. Mol Reprod Dev 75: 309-317

Geng Y, Yu Q, Whoriskey W, Dick F, Tsai KY, Ford HL, Biswas DK, Pardee AB, Amati B, Jacks T, Richardson A, Dyson N, Sicinski P (2001) Expression of cyclins E1 and E2 during mouse development and in neoplasia. Proc Natl Acad Sci USA 98: 13138-13143

Griffin SV, Pichler R, Wada T, Vaughan M, Durvasula R, Shankland S (2003) The role of cell cycle proteins in glomerular disease. Semin Nephrol 23: $569-582$

Hartwell LH, Kastan MB (1994) Cell cycle control and cancer. Science 266: 1821-1828

Herzig RP, Scacco S, Scarpulla RC (2000) Sequential serum-dependent activation of CREB and NRF-1 leads to enhanced mitochondrial respiration through the induction of cytochrome c. J Biol Chem 275: 13134-13141

Hsieh JK, Fredersdorf S, Kouzarides T, Martin K, Lu X (1997) E2F1-induced apoptosis requires DNA binding but not transactivation and is inhibited by the retinoblastoma protein through direct interaction. Genes Dev 11: $1840-1852$

Hu X, Zhang X, Zhong Q, Fisher AB, Bryington M, Zuckerman KS (2001) Differential effects of transforming growth factor on cell cycle regulatory molecules in human myeloid leukemia cells. Oncogene 20: 6840-6850

Jackman M, Firth M, Pines J (1995) Human cyclins B1 and B2 are localized to strikingly different structures: $\mathrm{B} 1$ to microtubules, $\mathrm{B} 2$ primarily to the Golgi apparatus. EMBO J 14: 1646-1654

Kim DM, Yang K, Yang BS (2003) Biochemical characterizations reveal different properties between CDK4/cyclin D1 and CDK2/cyclin A. Exp Mol Med 35: 421-430

Korzeniewski B (2006) AMP deamination delays muscle acidification during heavy exercise and hypoxia. J Biol Chem 281: 3057-3066

Lauricella M, Calvaruso G, Carabillo M, D’Anneo A, Giuliano M, Emanuele S, Vento R, Tesoriere G (2001) pRb suppresses camptothecin-induced apoptosis in human osteosarcoma Saos-2 cells by inhibiting c-Jun N-terminal kinase. FEBS Lett 499: 191-197

Law BK, Chytil A, Dumont N, Hamilton EG, Waltner-Law ME, Aakre ME, Covington C, Moses HL (2002) Rapamycin potentiates transforming growth factor beta-induced growth arrest in nontransformed, oncogenetransformed, and human cancer cells. Mol Cell Biol 22: 8184-8198

Li H, Jogl G (2009) Structural and biochemical studies of TIGAR (TP53induced glycolysis and apoptosis regulator). J Biol Chem 284: 1748-1754
Lim JH, Lee YM, Chun YS, Park JW (2008) Reactive oxygen speciesmediated cyclin D1 degradation mediates tumor growth retardation in hypoxia, independently of p21cip1 and hypoxia-inducible factor. Cancer Sci 99: 1798-1805

Macaluso M, Montanari M, Cinti C, Giordano A (2005) Modulation of cell cycle components by epigenetic and genetic events. Semin Oncol 32: 452-457

MacLachlan TK, Sang N, Giordano A (1995) Cyclins, cyclin-dependent kinases and cdk inhibitors: implications in cell cycle control and cancer. Crit Rev Eukaryot Gene Expr 5: 127-156

Malumbres M, Barbacid M (2009) Cell cycle, CDKs and cancer: a changing paradigm. Nat Rev Cancer 9: 153-166

Mandal S, Guptan P, Owusu-Ansah E, Banerjee U (2005) Mitochondrial regulation of cell cycle progression during development as revealed by the tenured mutation in Drosophila. Dev Cell 9: 843-854

Masamha CP, Benbrook DM (2009) Cyclin D1 degradation is sufficient to induce G1 cell cycle arrest despite constitutive expression of cyclin E2 in ovarian cancer cells. Cancer Res 69: 6565-6572

Matoba S, Kang JG, Patino WD, Wragg A, Boehm M, Gavrilova O, Hurley PJ, Bunz F, Hwang PM (2006) p53 regulates mitochondrial respiration. Science 312: 1650-1653

Mittnacht S (1998) Control of pRB phosphorylation. Curr Opin Genet Dev 8: $21-27$

Modestou M, Puig-Antich V, Korgaonkar C, Eapen A, Quelle DE (2001) The alternative reading frame tumor suppressor inhibits growth through p21-dependent and p21-independent pathways. Cancer Res 61: $3145-3150$

Mouysset J, Deichsel A, Moser S, Hoege C, Hyman AA, Gartner A, Hoppe T (2008) Cell cycle progression requires the CDC-48UFD-1/NPL-4 complex for efficient DNA replication. Proc Natl Acad Sci U S A 105: 12879-12884

Muta D, Makino K, Nakamura H, Yano S, Kudo M, Kuratsu J (2011) Inhibition of eIF4E phosphorylation reduces cell growth and proliferation in primary central nervous system lymphoma cells. J Neurooncol 101: $33-39$

Nevins JR (1992) E2F: a link between the Rb tumor suppressor protein and viral oncoproteins. Science 258: 424-429

Sheaff RJ, Groudine M, Gordon M, Roberts JM, Clurman BE (1997) Cyclin E-CDK2 is a regulator of p27Kip1. Genes Dev 11: 1464-1478

Sherr CJ (1996) Cancer cell cycles. Science 274: 1672-1677

Sherr CJ, Roberts JM (1995) Inhibitors of mammalian G1 cyclin-dependent kinases. Genes Dev 9: 1149-1163

Sweet S, Singh G (1995) Accumulation of human promyelocytic leukemic (HL-60) cells at two energetic cell cycle checkpoints. Cancer Res 55: 5164-5167

Thalmann I, Marcus NY, Thalmann R (1982) Adenine nucleotides of the organ of Corti under metabolic stress. Laryngoscope 92: 199-203

Thalmann R, Marcus NY, Thalmann I (1978) Adenylate energy charge, energy status, and phosphorylation state of stria vascularis under metabolic stress. Laryngoscope 88: 1985-1988

Touny LH, Banerjee PP (2006) Identification of both Myt-1 and Wee-1 as necessary mediators of the p21-independent inactivation of the cdc-2/ cyclin B1 complex and growth inhibition of TRAMP cancer cells by genistein. Prostate 66: 1542-1555

Varshavsky A (1997) The ubiquitin system. Trends Biochem Sci 22: 383-387

Viticchi C, Moresi R, Piantanelli L (1996) Assay of total protein kinase activity in mouse brain cortex. Boll Soc Ital Biol Sper 72: 317-324

Vogelstein B, Lane D, Levine AJ (2000) Surfing the p53 network. Nature 408: $307-310$

Wang S, Nath N, Minden A, Chellappan S (1999) Regulation of Rb and E2F by signal transduction cascades: divergent effects of JNK1 and p38 kinases. Embo J 18: 1559-1570

Weinberg RA (1995) The retinoblastoma protein and cell cycle control. Cell 81: $323-330$

Zhang HS, Postigo AA, Dean DC (1999) Active transcriptional repression by the Rb-E2F complex mediates G1 arrest triggered by p16INK4a, TGFbeta, and contact inhibition. Cell 97: 53-61

Zhu X, Kwon CH, Schlosshauer PW, Ellenson LH, Baker SJ (2001) PTEN induces $\mathrm{G}(1)$ cell cycle arrest and decreases cyclin D3 levels in endometrial carcinoma cells. Cancer Res 61: 4569-4575

This work is published under the standard license to publish agreement. After 12 months the work will become freely available and the license terms will switch to a Creative Commons Attribution-NonCommercial-Share Alike 3.0 Unported License. 